\title{
Author Correction: Density functional theory study of the role of benzylic hydrogen atoms in the antioxidant properties of lignans
}

\section{Quan V. Vo ${ }^{1,2}$, Pham Cam Nam ${ }^{3}$, Mai Van Bay ${ }^{4}$, Nguyen Minh Thong ${ }^{5}$, Nguyen Duc Cuong ${ }^{6}$ \& Adam Mechler iD $^{7}$}

Correction to: Scientific Reports https://doi.org/10.1038/s41598-018-30860-5, published online 17 August 2018

This Article contains errors in the Acknowledgements section.

"This work was supported by Vietnam National Foundation for Science and Technology Development (NAFOSTED) [grant number “104.06-2016.03” (3/2017/104/HĐTN)].”

should read:

"This research is funded by Vietnam National Foundation for Science and Technology Development (NAFOSTED) under grant number 104.06-2016.03."

(1) Open Access This article is licensed under a Creative Commons Attribution 4.0 International cc) License, which permits use, sharing, adaptation, distribution and reproduction in any medium or format, as long as you give appropriate credit to the original author(s) and the source, provide a link to the Creative Commons license, and indicate if changes were made. The images or other third party material in this article are included in the article's Creative Commons license, unless indicated otherwise in a credit line to the material. If material is not included in the article's Creative Commons license and your intended use is not permitted by statutory regulation or exceeds the permitted use, you will need to obtain permission directly from the copyright holder. To view a copy of this license, visit http://creativecommons.org/licenses/by/4.0/.

(C) The Author(s) 2019

\footnotetext{
${ }^{1}$ Department for Management of Science and Technology Development, Ton Duc Thang University, Ho Chi Minh City, Vietnam. ${ }^{2}$ Faculty of Applied Sciences, Ton Duc Thang University, Ho Chi Minh City, Vietnam. ${ }^{3}$ Department of Chemical Engineering, The University of Da Nang - University of Science and Technology, Da Nang City, Vietnam. ${ }^{4}$ Department of Chemistry, The University of Da Nang - University of Education, Da Nang City, Vietnam. ${ }^{5}$ The University of Da Nang, Campus in Kon Tum, 704 Phan Dinh Phung, Kon Tum, Vietnam. ${ }^{6}$ School of Hospitality and Tourism, Hue University, Hue City, Vietnam. ${ }^{7}$ Department of Chemistry and Physics, La Trobe University, Victoria, 3086, Australia. Correspondence and requests for materials should be addressed to Q.V.V. (email: vovanquan@tdt. edu.vn) or P.C.N. (email: pcnam@dut.udn.vn)
} 